\title{
A New Diagnostic Marker For Acute Pulmonary Embolism In Emergency Department: Mean Platelet Volume
}

\author{
Fahrettin Talay ${ }^{1}$, Tarık Ocak ${ }^{2}$, Aytekin Alcelik ${ }^{3}$, Kurşat Erkurann ${ }^{2}$ Akcan Akkaya ${ }^{4}$, \\ Arif Duran ${ }^{2}$, Abdullah Demirhan ${ }^{4}$, Ozlem Kar Kurt ${ }^{1}$, Zehra Asuk ${ }^{1}$
}

1.Department of Chest Diseases, Abant Izzet Baysal Medical Faculty, Bolu, Turkey

2.Department of Emergency Medicine, Abant Izzet Baysal Medical Faculty, Bolu, Turkey

3.Department of Internal Medicine, Abant Izzet Baysal Medical Faculty, Bolu, Turkey

4.Department of Anesthesiology and Reanimation, Abant Izzet Baysal Medical Faculty, Bolu, Turkey

\begin{abstract}
Objective: To investigate the diagnostic importance of mean platelet volume (MPV) on acute pulmonary embolism (APE) in the emergency Department (ED).

Methods: Subjects were selected from patients admitted to ED with clinically suspected APE. Demographic, anthropometric and serologic data were collected for each patient.

Results: A total of 315 consecutive patients were analyzed, including 150 patients (53.44 \pm 15.14 y; 92 men/58 women) in APE group and 165 patients (49.80 $\pm 13.76 y ; 94$ men/71 women) in the control group. MPV in the APE group was significantly higher than in the control group $(9.42 \pm 1.22 \mathrm{fl}$ vs. $8.04 \pm 0.89 \mathrm{fl}, \mathrm{p}<0.0001)$. The best cut-off values for MPV when predicting APE in patients with clinically suspected APE presenting at the ED were $8.55 \mathrm{fl}$ (sensitivity 82.2\%; specificity $52.3 \%)$.
\end{abstract}

Conclusions: MPV is a helpful parameter for the diagnosis of APE in ED, for the first time in the literature.

Key Words: Acute pulmonary embolism, emergency department, mean platelet volume, thrombus.

African Health Sciences 2014;14(1): 94-99 http://dx.doi.org/10.4314/ahs.v14i1.15

\section{Introduction}

Acute Pulmonary Embolism (APE) is one of the serious diseases in the emergency department (ED) with high mortality diseases estimates of up to $10 \%$ 1. The diagnosis of APE can be very difficult in the $\mathrm{ED}$ and the waiting time for a first appointment in ED before starting special treatment can be very long. The diagnosis of APE can be difficult because of the nonspecific signs and symptoms, which include cough, dyspnea, tachypnea, hemoptysis and pleuritic chest pain. Some blood parameters, echocardiography and computed tomography can be used for the diagnosis of $\mathrm{APE}$ in $\mathrm{ED}^{2,3}$. We know that an ideal diagnostic test should be accurate, safe, readily available, and cost-

\section{Correspondence author:}

Fahrettin Talay

Abant Izzet Baysal University, Medical Faculty

Department of Chest Disease, Bolu, Turkey.

E-mail: abanttip14@gmail.com

Telephone number: +903742534618

Fax number: +903742534615 effective and should have wide spread acceptance. At present, none of the available diagnostic tests meets all these criteria.

The mean platelet volume (MPV) is potentially one of the most important biomarkers of platelet activity and calculated by automatic blood count equipment during routine blood counts ${ }^{4}$. MPV is an indicator of platelet activation and there is strong evidence indicating that MPV is an important variable and that larger platelets have a higher thrombotic potential ${ }^{5,6}$. Elevated MPV has been recognized as an independent risk factor for different clinical conditions ${ }^{7-9}$. Recently, previous studies clearly showed that MPV was associated with acute deep venous thrombosis (DVT) and high levels of MPV might increase the specificity of D-dimer for exclusion of $\mathrm{DVT}^{10,11}$. APE is a common complication of DVT, $50 \%$ of APE cases arise from thrombus in the deep venous system of the lower extremities ${ }^{12}$. In this aspect, MPV may have association with $\mathrm{APE}{ }^{13}$. In one study, MPV was found to be an independent predictor of early death in APE ${ }^{14}$ and another study speculated that it can be used for the determination of disease severity ${ }^{15}$. 
However, to the best of our knowledge, studies to evaluate the early time diagnostic importance of MPV in APE patient has not been reported in the literature previously. Consequently, the aim of this study was to investigate whether there is an association between MPV and APE in the ED.

\section{Methods}

This retrospective study was conducted in Abant Izzet Baysal University Education and Research Hospital. Polyclinic and admission files as well as automation system records of patients admitted to the emergency services between January 2008 and December 2012. This study was approved by the ethics committee of Abant Izzet Baysal University Medical School.

In this period, the files and records of 892 cases evaluated with the pre-diagnosis of APE were reached. Three hundred sixty-two of these cases were excluded due to missing information; two hundred fifteen cases were excluded due to the exclusion criteria. Recruitment, exclusion, and subsequent grouping of all patients are shown in the flowchart (Figure 1).

Fioure 1. Recruitment. exclusion. and subseauent orouning of all natients

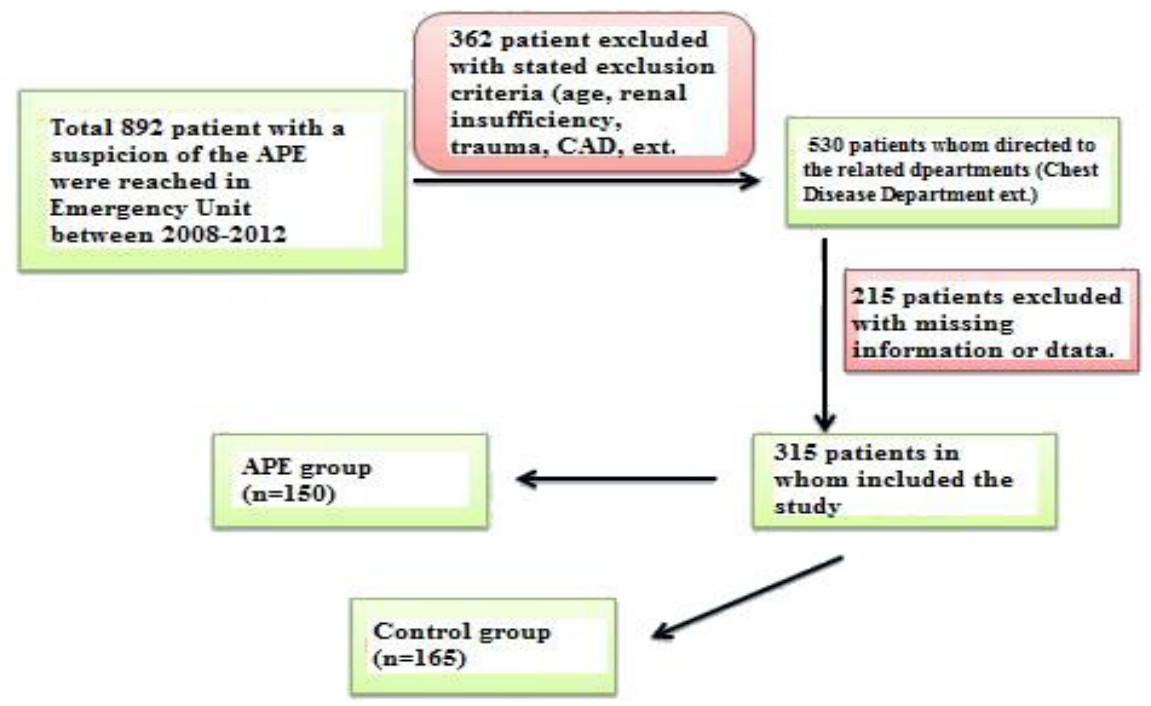

A total of 315 consecutive patients who had been admitted to the Abant University Education and Research Hospital emergency clinic with clinically suspected APE (pain/sudden-onset dyspnea in the past week) were recruited to participate in the study, and who had fulfilled the inclusion criteria, were enrolled. APE was confirmed by thoracic multislice computed tomography showing complete or partial filling defect in pulmonary branches or by ventilation/perfusion pulmonary cintigraphy showing a high probability of PTE. One hundred sixty five patients who presented to the emergency unit with dyspnea and who had a previous diagnosis of APE were excluded from the APE diagnosis group and used as the control group. 51 patients have been put into intensive care unit, while 99 patients have been placed in the Chest disease department service.

The exclusion criteria's were as follows: age $>65$, coronary artery diseases, acute coronary syndrome, congestive heart failure, significant valvular heart disease, pacemaker implantation, atrial flutter or fibrillation, peripheral vascular diseases, pulmonary or neurological disease, pericarditis, malignancy, infection, pregnancy, overt hypothyroidism or hyperthyroidism, chronic renal or hepatic disease and overt/active hematological disorders.

Age, gender, leukocyte and thrombocyte counts at the time of hospital admission, and MPV values were recorded. The MPV was determined on arrival at the ED through the brachial vein, collected into tubes containing ethylenediaminetetraacetic acid (EDTA). These blood samples were analyzed within 1 hours of venipuncture with an automatic blood counter a Sysmex XT 2000i (Roche Diagnostics, Tokyo, Japan) used for whole blood analysis. The expected values for MPV in our laboratory ranged from 7.0 to $12.0 \mathrm{fl}$. The analytic coefficient of variation for MPV ranged from 2.2 to $1.1 \%$.

The results are presented as mean \pm SD or frequency (percentage) as appropriate. A $\chi^{2}$ tests or Fisher exact 
test, as appropriate, was used for the statistical analysis of categorical variables. Continuous variables were compared using by using the Student t test or Wilcoxon rank sum test as appropriate. One-way analysis of variance (ANOVA) with Fisher LSD comparisons was used to compare more than two parametric variables. The variables with univariate comparisons of $\mathrm{p}<0.05$ between APE and control group were eligible for inclusion in an entry selection multiple logistic regression model, which identified the clinical factors in the ED that were potential predictors of APE. To determine the accuracy and respective best cut-off values of MPV for predicting APE, the receiver operating characteristic (ROC) curves and their corresponding areas under the curve were used. A p value of $<0.05$ was considered statistically significant. A common statistical package (SPSS 17.0 for Windows; SPSS, Chicago, Illinois, USA) was used to perform all statistical tests.

\section{Results}

150 patients $53.44 \pm 15.14$ (92 men 58 women) with pulmonary embolism diagnosis (APE group) and 165 patients $49.80 \pm 13.76$ (94 men and 71 women) without pulmonary embolism diagnosis (Control group) have been included in the study.

The demographic and clinical characteristics of the study patients are depicted in table 1.

Table 1. The baseline characteristics of the patients.

Table 1. The demographic and clinical characteristics of the study patients

\begin{tabular}{lccc}
\hline & $\begin{array}{c}\text { APE } \\
(\mathrm{n}=150)\end{array}$ & $\begin{array}{c}\text { Control } \\
(\mathrm{n}=165)\end{array}$ & $\mathrm{P}$ \\
\hline Age (years) & $53.44 \pm 15.14$ & $49.80 \pm 13.76$ & 0.231 \\
Sex (male/\%) & $92 / 61.3 \%$ & $94 / 56.9 \%$ & 0.152 \\
Hypertension (\%) & $39.4 \%$ & $31.1 \%$ & 0.089 \\
Diabetes (\%) & $18.3 \%$ & $14.2 \%$ & 0.072 \\
Smoking (\%) & $47.3 \%$ & $28.3 \%$ & 0.012 \\
DVT history (\%) & $8.2 \%$ & $3.2 \%$ & 0.031 \\
Ischemic Heart & $13.2 \%$ & $11.2 \%$ & 0.061 \\
Disease (\%) & & & \\
\hline
\end{tabular}

The measured hematological parameters are presented in Table 2.

Table 2. The measured hematological parameters of both groups

\begin{tabular}{lccc}
\hline & $\begin{array}{c}\text { APE } \\
\mathrm{n}=150\end{array}$ & $\begin{array}{c}\text { Control } \\
\mathrm{n}=165\end{array}$ & $\mathrm{P}$ \\
\hline Platelet $\left(\mathrm{x} 10^{9} / \mathrm{L}\right)$ & $286.5 \pm 33.5$ & $281.5 \pm 35.8$ & 0.435 \\
$\mathrm{MPV}(\mathrm{fL})$ & $9.42 \pm 1.22$ & $8.04 \pm 0.89$ & $\mathbf{0 . 0 0 0}$ \\
$\mathrm{Hgb}(\mathrm{g} / \mathrm{d} \mathbf{L})$ & $12.0 \pm 1.2$ & $12.1 \pm 1.4$ & 0.563 \\
$\mathrm{Hct}$ & $35.32 \pm 3.71$ & $35.93 \pm 2.79$ & 0.716 \\
$\mathrm{WBC}\left(\mathrm{x} 10^{9} / \mathrm{L}\right)$ & $7.71 \pm 2.43$ & $7.68 \pm 1.81$ & 0.756 \\
$\mathrm{RDW}$ & $14.08 \pm 1.57$ & $13.97 \pm 1.12$ & 0.134 \\
$\mathrm{D}-\mathrm{Dimer}$ & $4.98 \pm 9.6$ & $0.62 \pm 0.18$ & $\mathbf{0 . 0 0 0}$ \\
\hline
\end{tabular}

In terms of the focus of the study, hemoglobin, neutrophil count, mean corpuscular volume (MCV), red cell distribution width (RDW), platelet, white blood cell (WBC), and lymphocyte counts were similar in both groups. MPV in the APE group was significantly higher than in the control group $(9.42 \pm 1.22 \mathrm{fl}$ vs. $8.04 \pm 0.89 \mathrm{fl}$, $\mathrm{p}<0.0001$; figure 2). 
Figure 2. The MPV levels of two groups (1: APE 2: Control).

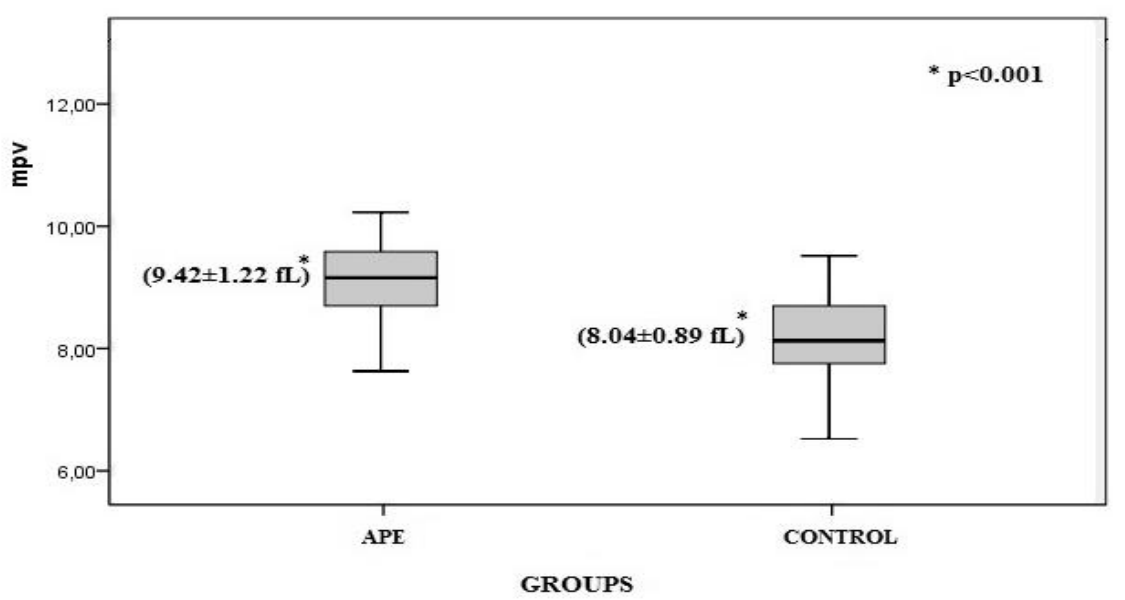

The D-dimer levels of the patients were as follows: 4.98 \pm 9.6 (median; 2.74 minimum; 1.01 maximum;

78.00) in APE group, $0.62 \pm 0.18$ (median; 0.29. minimum; 0.00 maximum; 0.96) in control group. Statistically significant difference has been observed between the groups $(\mathrm{p}<0.05)$.

In order to assess the potential independent predictors of SVT in patients with palpitation, multiple logistical regression analysis was performed and included data yielding significant differences $(\mathrm{p}<0.05)$ between the APE group and the control group individually. After adjusting for demographic and all hematologic factors (age, gender, smoking, D-dimer, white blood cell count, hemoglobin, hematocrit, neutrophil count, MCV, RDW, MPV, leucocyte count and platelet count), it was found that just MPV and D-dimer showed significance in a binary logistical regression model $(7.497,95 \%$ CI (6.712 to 10.325), $\mathrm{p}=0.012 ; 1.070,95 \%$ CI 1.019-1.124, $\mathrm{p}=0.0069$, respectively $)$.

The ROC curve analysis of MPV when predicting APE in patients with clinically suspected APE (pain/suddenonset dyspnea in the past week) were constructed and the areas under the curve was found to be 0.634 (95\% CI 0.596 to $0.702, \mathrm{p}=0.023$; figure 3 ).

Figure 3. ROC curve analysis.

\section{ROC Curve}

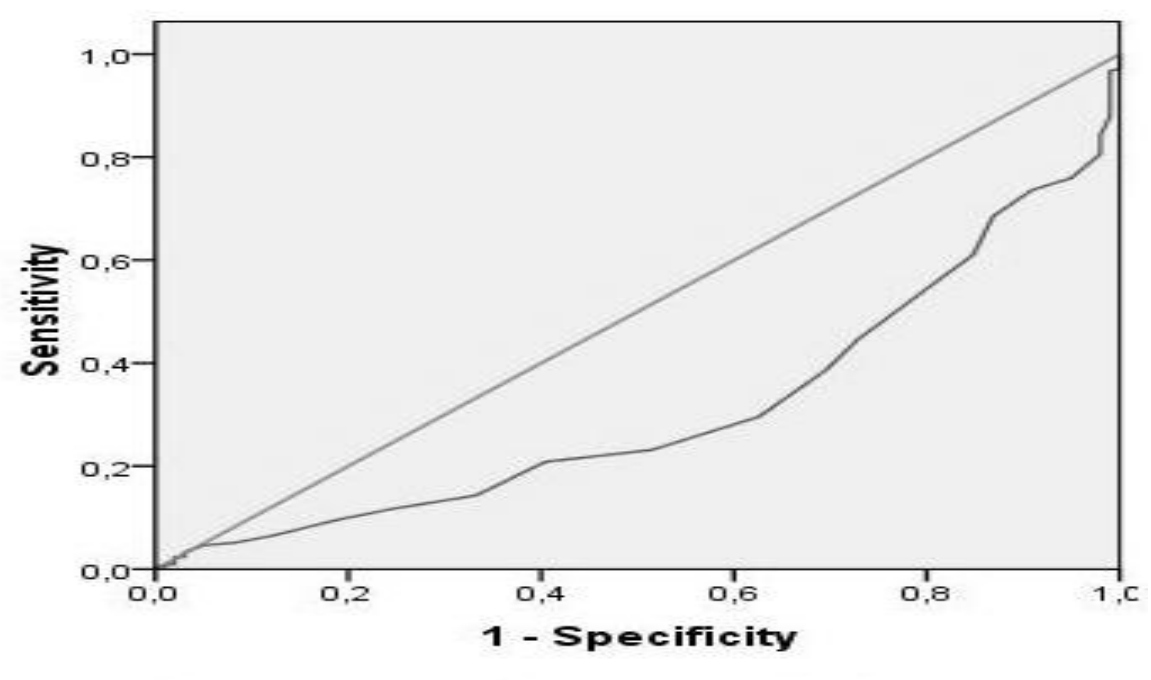

Diagonal segments are produced by ties. 
The best cut-off values for MPV when predicting APE in patients with clinically suspected APE presenting at the ED were $8.55 \mathrm{fl}$ (sensitivity $82.2 \%$; specificity $52.3 \%)$.

\section{Discussion}

This study clearly demonstrated that MPV was significantly higher in patients with APE in ED than in control subject. In addition, we showed that MPV was an independent predictor of APE. To the best of our knowledge, this the first study that evaluate the relationship between MPV and APE in ED.

Previous studies have shown that MPV is a marker of platelet function and is positively associated with indicators of platelet activity ${ }^{5-7,9}$. Recently, clearly known that increased MPV is shown more reactive platelets. We also known that increased in MPV is closely correlated with thrombosis and to reflect thrombosis burden in different condition and increase in MPV has been identified as an independent risk factor of recurrent vascular events ${ }^{9-11,16}$. Previous studies showed that there is the hypercoagulable/prothrombotic state in APE, which is also important in development of thrombosis ${ }^{17}$. Together with this, APE is a frequent and sometimes mortal complication of deep venous thrombosis, $50 \%$ of APE cases arise from thrombi in the deep venous system of the lower extremities ${ }^{12}$. With this aspect, the pathophysiologic relationship with APE and MPV is to be expected. The result of this study, clearly demonstrated the relationship between APE and MPV, first time in the literature. Therefore, increased MPV could be regarded as a diagnostic marker for APE in emergency department.

APE is a life threatening disease, with approximately $10 \%$ mortality rate ${ }^{18}$. It is difficult to preview the risk and to evaluate the APE patients in clinical practice. APE diagnosis is complicated because there are many symptoms and observations at the application ${ }^{19}$. APE's are the most common encountered diseases seen in emergency department. The clinical scoring algorithms, serum tests, ECG, chest radiography, echocardiography, lower extremity Doppler ultrasonography, nuclear ventilation-perfusion cintigraphy, computer-assisted pulmonary angiography tomography, conventional chest angiography, and magnetic resonance are used for the diagnosis of acute pulmonary embolism in emergency units ${ }^{20}$. These examination methods may not be performed in every center and they are expensive and time-consuming methods. The ideal diagnostic test should be accurate, safe, readily available, and costeffective and should have wide spread acceptance. MPV is a parameter easily calculated by automatic blood count equipment during routine blood counts in all ED services. However, most of time MPV is not generally taken into consideration by physicians. Here, we observed that MPV was significantly higher in patients with APE in ED than in control subject. Also, this study concluded that MPV was an independent predictor of APE. We hypothesis that all of these relation can be helpful in ED for the diagnosis of SVT. MPV may be used at higher levels for PE diagnosis algorithms.

\section{Limitation}

The main limitation of our study was the small sample size. A small sample size can result in low statistical power for equivalency testing, leading to false-negative results. However, establishing a study group without comorbidities is difficult. Second, our study had a cross-sectional design. Future prospective much larger multicenter studies are required to confirm our results. Because of the retrospective nature of data collection, echocardiographic parameters were not obtained concomitantly with blood sampling. Also, we were unable to evaluate some factors, such as hormone replacement therapy and some drugs, which have been effected to the MPV, because data on these variables were not collected. We had no exact information about the time of blood sampling in the ED. The heart rhythm and rate at the time of baseline blood sampling was not fully known. Together with it, we cannot apply our results for general population due to the broad exclusion criteria.

\section{Conclusion}

The present report is the first study evaluating the relationship between MPV and APE in ED. Consequently, the present study described that MPV is a helpful parameter for the diagnosis of APE in the emergency department, for the first time in literature. 


\section{References}

1. Kearon C. Natural history of venous thromboembolism. Circulation 2003;107(23 Suppl 1):I22-30.

2. Roy PM, Meyer G, Vielle B, Le Gall C, Verschuren F, Carpentier F, et al. Appropriateness of diagnostic management and outcomes of suspected pulmonary embolism. Ann Intern Med 2006;144(3):157-64.

3. Wells PS, Anderson DR, Rodger M, Stiell I, Dreyer JF, Barnes D, et al. Excluding pulmonary embolism at the bedside without diagnostic imaging: management of patients with suspected pulmonary embolism presenting to the emergency department by using a simple clinical model and d-dimer. Ann Intern Med 2001;135(2):98-107.

4. Gawaz M, Langer H, May AE. Platelets in inflammation and atherogenesis. J Clin Invest 2005;115(12):337884.

5. Bath PM, Butterworth RJ. Platelet size: measurement, physiology and vascular disease. Blood Coagul Fibrinolysis 1996;7(2):157-61.

6. Erdogan D, Tayyar S, Icli A, Uysal BA, Varol E, Ozaydin $\mathrm{M}$, et al. Elevated mean platelet volume is associated with impaired coronary microvascular function in patients with idiopathic dilated cardiomyopathy. Platelets 2012;23(3):177-83.

7. Bath P, Algert C, Chapman N, Neal B. Association of mean platelet volume with risk of stroke among 3134 individuals with history of cerebrovascular disease. Stroke 2004;35(3):622-6.

8. Huczek Z, Kochman J, Filipiak KJ, Horszczaruk GJ, Grabowski M, Piatkowski R, et al. Mean platelet volume on admission predicts impaired reperfusion and longterm mortality in acute myocardial infarction treated with primary percutaneous coronary intervention. J Am Coll Cardiol 2005;46(2):284-90.

9. Ozlu MF, Ozturk S, Ayhan SS, Tosun M, Alcelik A, Erdem A, et al. Predictive value of mean platelet volume in young patients with non-ST-segment elevation acute coronary syndromes: a retrospective observational study. Anadolu Kardiyol Derg 2013;13(1):57-61.
10. Canan A, Halicioglu SS, Gurel S. Mean platelet volume and D-dimer in patients with suspected deep venous thrombosis. J Thromb Thrombolysis 2012;34(2):283-7. 11. Gulcan M, Varol E, Etli M, Aksoy F, Kayan M. Mean platelet volume is increased in patients with deep vein thrombosis. Clin Appl Thromb Hemost 2012;18(4):42730.

12. Tzoran I, Saharov G, Brenner B, Delsart D, Roman $\mathrm{P}$, Visona A, et al. Silent pulmonary embolism in patients with proximal deep vein thrombosis in the lower limbs. J Thromb Haemost 2012;10(4):564-71.

13. Varol E, Icli A, Uysal BA, Ozaydin M. Platelet indices in patients with acute pulmonary embolism. Scand J Clin Lab Invest 2011;71(2):163-7.

14. Kostrubiec M, Labyk A, Pedowska-Wloszek J, Hrynkiewicz-Szymanska A, Pacho S, Jankowski K, et al. Mean platelet volume predicts early death in acute pulmonary embolism. Heart 2010;96(6):460-5.

15. Gunay E, Ulasli SS, Kacar E, Halici B, Unlu E, Tunay $K$, et al. Can platelet indices predict obstruction level of pulmonary vascular bed in patients with acute pulmonary embolism? Clin Respir J 2013.

16. Acikgoz N, Karincaoglu Y, Ermis N, Yagmur J, Atas $\mathrm{H}$, Kurtoglu E, et al. Increased mean platelet volume in Behcet's disease with thrombotic tendency. Tohoku J Exp Med 2010;221(2):119-23.

17. Spencer FA, Gore JM, Lessard D, Douketis JD, Emery C, Goldberg RJ. Patient outcomes after deep vein thrombosis and pulmonary embolism: the Worcester Venous Thromboembolism Study. Arch Intern Med 2008;168(4):425-30.

18. Wang ZL. Acute pulmonary embolism: the clinical conundrum. Chin Med J (Engl) 2012;125(2):352-66.

19. Aujesky D, Jimenez D, Mor MK, Geng M, Fine MJ, Ibrahim SA. Weekend versus weekday admission and mortality after acute pulmonary embolism. Circulation 2009;119(7):962-8.

20. Ballantine M, Bhimani M, Milne WK. Diagnostic approach to pulmonary embolism in a rural emergency department. Can J Rural Med 2012;17(1):17-20. 